\title{
UM OLHAR SOBRE A ORIGEM DA CIÊNCIA DA INFORMAÇÃO: INDÍCIOS EMBRIONÁRIOS PARA SUA CARACTERIZAÇÃO IDENTITÁRIA
}

\author{
Jonathas Luiz Carvalho Silva ${ }^{\mathrm{i}}$ \\ Gustavo Henrique de Araújo Freire ${ }^{\text {ii }}$
}

\begin{abstract}
Resumo: Discute sobre fundamentos sociais, científicos e cotidianos que deram vazão para o advento da Ciência da Informação, visando conceber suas características identitárias. A condição problematológica do presente trabalho pode ser sintetizada a partir da seguinte pergunta: Quais os fatores diretos e/ou indiretos que deram vazão para o surgimento da Ciência da Informação? Quais as influências desses fatores para a construção e caracterização da identidade da Ciência da Informação? Tem como objetivo discutir sobre os diversos fenômenos sociais, acadêmicos e científicos que direta e/ou indiretamente promoveram origem a Ciência da Informação. Metodologicamente, o artigo apresenta uma pesquisa exploratória no contexto da investigação histórica por meio de uma revisão bibliográfica. Conclui que diversos fatores auxiliaram na origem e construção da Ciência da Informação mostrando a sua característica de ciência pós-moderna, sendo possível observar diversas características identitárias a partir dos elementos que deram vazão a origem da Ciência da Informação, tais como: identidade histórica (relação entre Biblioteconomia e Ciência da Informação); identidade de projeto (a Documentação de Otlet e La Fontaine); identidade partilhada (contribuição dos EUA e do continente europeu para criação da Ciência da Informação) e identidade institucional (criação de associações em Ciência da Informação).
\end{abstract}

Palavras-chave: Ciência da Informação. Origem. Identidade.

\section{A LOOK AT THE ORIGIN OF INFORMATION SCIENCE: EVIDENCE FOR EMBRYONIC IDENTITY CHARACTERIZATION}

\begin{abstract}
Discusses social foundations, scientific and everyday that have given rise to the advent of Information Science, in order to conceive their identity characteristics. Problematologica The condition of this work can be synthesized from the following question: What are the direct factors and / or indirect that have given rise to the emergence of information science? What are the influences of these factors for the construction and characterization of the identity of Information Science? It aims to discuss the various social phenomena, academic and scientific directly and / or indirectly promoted the rise of information science. Methodologically, the article presents an exploratory research in the context of historical research through a literature review. It concludes that several factors helped the origin and foundation of Information Science showing its characteristic of postmodern science, it is possible to observe various features of identity from the elements that gave rise to flow of information science, such as historical identity (relationship of Library and Information Science), identity design (Documentation of Otlet and La Fontaine); shared identity (U.S. contribution to the European continent and the creation of the Information Science) and institutional identity (creation of associations in Information Science).
\end{abstract}

Keywords: Information Science. Origin. Identity.

\footnotetext{
${ }^{i}$ Universidade Federal do Ceará - Campus Cariri. jonathascarvalhos@yahoo.com.br.

${ }^{i i}$ Universidade Federal da Paraíba. ghafreire@gmail.com.

Recebido em: 25/08/2011; aceito para publicação em: 24/02/2012.
} 


\section{INTRODUÇÃO}

É no século XX que acontece o advento da Ciência da Informação emergindo como ciência e prática com um papel de destaque na sociedade contemporânea que, teve a partir da Revolução Científica do século XVI, e, principalmente, a Revolução Científica do século XIX subsídios para existir. Vale ressaltar que a Ciência da Informação se configura como um dos pressupostos que surgem com a perspectiva de diminuir os rumos de incerteza e insegurança da sociedade pós-moderna, especialmente no que tange as questões informacionais.

A condição problematológica do presente trabalho pode ser sintetizada a partir da seguinte pergunta: Quais os fatores diretos e/ou indiretos que deram vazão para o surgimento da Ciência da Informação? Quais as influências desses fatores para a construção e caracterização da identidade da Ciência da Informação? O presente trabalho tem como objetivo discutir sobre os diversos fenômenos sociais, acadêmicos e científicos que direta e/ou indiretamente promoveram origem a Ciência da Informação.

Assim, a noção de origem da Ciência da Informação implica em duas estruturas básicas: a primeira está relacionada a antecessores sociais e científicos que direta e indiretamente contribuíram para o advento da Ciência da Informação (o que provoca a manifestação de um dado fenômeno, causa, motivo e procedência) e acontecimentos institucionais, técnicos e científicos que marcadamente promoveram o caminhar da Ciência da Informação (o surgimento ou início de alguma coisa e princípio, começo e ascendência). ${ }^{3}$

Essa classificação de origem visa facilitar as discussões sobre a Ciência da Informação, bem como verificar as diversas concepções que possibilitaram o surgimento da área. Vale ressaltar quão difícil é precisar o surgimento da Ciência da Informação, mesmo sendo considerada uma área científica recente. Como afirmam Couzinet, Silva e Menezes (2007, p. 1) "a Ciência da Informação no mundo, desde sua criação, vivencia uma crise de identidade e suas fronteiras com outras disciplinas não estão claramente delimitadas".

É preciso ressaltar que a não delimitação precisa da Ciência da Informação se configura em uma marca imanente das ciências pós-modernas, o que deve ser concebido como característica e não como um aspecto negativo e que poderia levar a críticas de não cientificidade da área.

\footnotetext{
3 Entenda-se o termo estrutura como um conjunto de fatores que analisados isoladamente constituem uma parcela de contribuição para o advento da CI. Porém, a partir de uma compreensão coletiva deste conjunto, é possível identificar com mais precisão os motivos e causas das quais a CI surgiu e se desenvolveu.
} 


\section{PRIMEIROS INDÍCIOS SOCIAIS E CIENTÍFICOS: IDENTIDADE HISTÓRICA E CONTRASTIVA DA CIÊNCIA DA INFORMAÇÃO}

Com efeito, iniciando pela primeira estrutura de origem concebida (o que provoca a manifestação de um dado fenômeno, causa, motivo e procedência), o fundamento primordial que caracteriza o surgimento da Ciência da Informação é a necessidade de refletir sobre os procedimentos de organização, registro e difusão tendo como centralidade a informação em si e seus fluxos, visando compreender os fundamentos dessas técnicas organizacionais que já existiam antes da Ciência da Informação, mas que vem aferindo efetiva importância na história da humanidade, especialmente a partir da II Guerra Mundial. (ANDRADE; OLIVEIRA, 2005).

É pertinente ressaltar que o ser humano no decorrer da história vem tentando arregimentar formas de classificar, registrar, organizar e difundir a informação em suas mais diversas áreas. Porém, havia a necessidade premente de uma área específica para tratar de problemas relativos a informação, enquanto um fenômeno social.

Isto quer dizer que na história da humanidade, sempre foi preciso pensar a possibilidade de uma ciência para organizar o conhecimento e propor procedimentos de organização e disseminação da informação, principalmente a partir da explosão informacional do século XX.

De acordo com Morin (1990) para pensar os desafios da complexidade humana, faz-se necessário pensar princípios norteadores para organização do conhecimento.

E o que significa a criação de uma área para tratar de problemas informacionais e organizar o conhecimento? Em tese, significa atentar para uma área que estabeleça uma flutuação entre as mais diversas áreas do conhecimento. Uma área que possua intersecção no contexto da organização do conhecimento e disseminação da informação, seja no contexto científico, seja no contexto do cotidiano da sociedade global.

Em outras palavras, a Ciência da Informação vem com a perspectiva de satisfazer áreas do conhecimento científico, profissionais das mais diversas áreas (de nível superior ou não), indivíduos e instituições sociais, políticas, econômicas, culturais e educativas diversas.

Em suma, segundo Saracevic (1996, p. 43) "problemas informacionais existem há longo tempo, sempre estiveram mais ou menos presentes, mas sua importância real ou percebida mudou e essa mudança foi responsável pelo surgimento da CI”. 
O segundo ponto que contribuiu para o advento da Ciência da Informação está concentrado em disciplinas antecessoras, tais como: Biblioteconomia e Documentação. ${ }^{4}$

A Biblioteconomia é um marco no contexto da organização do conhecimento por ser considerada uma área milenar, especialmente no que tange a organização e registro das informações nas coleções existentes nas bibliotecas. As bibliotecas, desde o seu limiar, apresentavam procedimentos, mesmo que ainda rudimentares de organização, registro e classificação para assegurar a memória da humanidade através de procedimentos voltados para o acesso às informações, ainda que esse acesso, por longo período histórico, estivesse restrito a segmentos sociais específicos.

Lemos (2005) destaca que as bibliotecas e seus procedimentos organizacionais existiram desde o terceiro milênio a. C., em um templo na cidade babilônica de Nipur sendo colocadas tabulas de argila com escrita cuneiforme. O autor destaca também a biblioteca de Assurbanipal, rei da Assíria, que viveu entre de 668 a 627 a. C. localizada em seu palácio de Nínive e contava com cerca de 25 mil tabulas atestando que a composição do acervo da biblioteca em questão foi feita através de transcrições e textos que Assurbanipal coletava sistematicamente em seu reino. Destaca-se ainda as bibliotecas egípcias (templo de Hórus em Edfu e a biblioteca de Alexandria fundada no século III a. C.).

$\mathrm{Na}$ Idade Média, as bibliotecas passaram a ser controladas, em caráter particular pela Igreja. A vantagem é que boa parte do acervo das bibliotecas religiosas (Ocidente e Oriente Médio) preservaram para as gerações vindouras o legado histórico-cultural da Antiguidade Greco-romana. Inclusive, as bibliotecas religiosas da Idade Média contribuíram para a fundação das bibliotecas universitárias européias a partir do século XVIII. A desvantagem é que a Igreja não tinha interesse em disseminar a informação por receio de que a sociedade questionasse os pressupostos religiosos, principalmente a partir da tradução e interpretação dos textos bíblicos. (BURKE, 2002).

É a partir do século XV, com a criação da imprensa e da ocorrência do Renascimento que as bibliotecas passam a ter maior independência no que tange ao registro, disseminação e acesso a informação. Porém, como afirma Burke (2002, p. 173) "parece inevitável que nas atividades humanas todas as soluções de um problema mais cedo ou mais tarde acabem gerando outros problemas."

\footnotetext{
${ }^{4}$ Embora a Biblioteconomia e a Documentação tenham sido marcos para criação da Ciência da Informação, é interessante destacar a Arquivologia (JARDIM; FONSECA 1992) e a Museologia (WERSIG, 1993) como setores que apresentam relações com a Ciência da Informação.
} 
Entende-se que se o processo da biblioteca concernente a difusão e acesso à informação começava a se ampliar promovendo maior visibilidade social a biblioteca, o contexto da organização começa a perder espaço.

Ortega (2004, p. 3) confirma esta afirmação quando argumenta:

[...] Esta entidade manteve-se inalterada até a Idade Moderna quando a produção dos livros tipográficos, entre outros motivos, levou a que as bibliotecas passassem a existir separadamente e a adquirir maior relevância enquanto elemento social. A tecnologia da impressão promoveu uma primeira modificação na atividade da organização e preservação de documentos, uma vez que, aos poucos, foi retirada da biblioteca a tarefa de reprodução de manuscritos realizada pelos copistas, que passou a ser feita em oficinas especializadas. Apesar do crescente destaque social vivido pela biblioteca a partir de então, pode-se dizer que o trabalhador da biblioteca perdeu certa responsabilidade, cumplicidade e envolvimento com os documentos, já que não realizava mais a reprodução dos mesmos e a compreensão e organização dos conteúdos que lhe é decorrente.

A partir do século XVI, a biblioteca, particularmente a pública, ganha um status de instituição socializadora e passível de acesso ao público, haja vista a grande quantidade de indivíduos que eram alfabetizados na Europa. É preciso considerar que a biblioteca passa a ter uma autonomia social.

Dessa forma, verifica-se uma primeira marca identitária para se pensar o advento da Ciência da Informação, pois com a alfabetização de diversos indivíduos, a necessidade de técnicas de organização e difusão da informação foi se tornando mais latentes. Por isso, o surgimento dos catálogos, das bibliografias e de outros instrumentos organizacionais viria aprimorar atividades documentais e informacionais no seio das bibliotecas com vistas a ampliar o acesso da informação aos usuários.

Ocorre que até o início do século XIX a ideia de uma Biblioteconomia técnica e cientificamente constituída ainda era rudimentar. Embora existissem práticas bibliotecárias, ainda não eram práticas amplamente estruturadas por métodos consistentes. De acordo com o comentário de Lahary (1997) o termo Biblioteconomia passou a ser utilizado apenas em 1839 na obra intitulada "Bibliothéconomie: instructions sur l'arrangement, la conservation e l'administration des bibliothèques", publicada pelo livreiro e bibliógrafo Léopold-AugusteConstantin Hesse. Isso significa dizer que as proposições sobre a constituição das bibliotecas, especialmente a partir da Idade Moderna, foram cruciais para a estruturação da Biblioteconomia a partir de um corpo técnico e artístico. Em outras palavras, uma área específica que contemplasse um processo de organização de acervos em bibliotecas.

Destarte, a Idade Moderna, especialmente o século XIX, é um marco em que a Biblioteconomia, aprimora um conjunto de estudos técnicos e epistemológicos para organização do conhecimento e acerca de como tratar a informação. Alguns marcos 
biblioteconômicos são significativos para promover o advento da CI, mesmo que de forma indireta. De acordo com Tálamo e Smit (2007) alguns estudiosos se destacam: Gabriel Naudé e Melvil Dewey.

Iniciando por Naudé (2000), propunha um modelo de biblioteca pública que atuasse como instrumento de ação e preservação cultural. A proposta desse modelo está em seu livro intitulado Advis pour dresser une bibliothèque (Conselhos para Organizar uma biblioteca) que apresentou ao parlamento francês em 1627. Naudé já ponderava a possibilidade de uma biblioteca que agregasse todo o conhecimento do mundo ou pelo menos uma biblioteca que pudesse agregar uma ampla dimensão de acervo e catálogos. Isso significava dizer que Naudé era um entusiasta do discurso de que a biblioteca deveria ser acessível a todos sem distinção de raça, credos ou intelectualidades.

Para tanto, Naudé pensou em diversos aspectos para compor seu discurso de uma "biblioteca para todos" pautando a partir dos seguintes tópicos:

a) o motivo e interesse que se deve ter em construir bibliotecas;

b) o modo de se informar e como aprender a organizar uma Biblioteca;

c) a quantidade necessária de livros que deve possuir uma biblioteca;

d) a qualidade e as condições que devem ter os livros;

e) os meios de poder recuperá-los; A situação do local e onde manter os livros;

f) a ordem e concordância dos livros;

g) o ornamento e a decoração que deve possuir uma biblioteca;

h) qual o objetivo principal desta biblioteca.

Como é possível observar Naudé já se preocupava com questões que hoje são muito comuns no bojo da Ciência da Informação, tais como: organização, difusão e acesso à informação; procedimentos para recuperação de informação, quantidade e qualidade de livros em uma biblioteca.

É pertinente ressaltar que Naudé com o desenvolvimento desta obra mostra quão importante é uma reorganização bibliográfica para a apropriação do saber. (GÓMEZ, 2000)

Como Naudé primava pelo acesso irrestrito a informação implicava afirmar que era a favor da liberdade de expressão e que o usuário deveria ter acesso a conteúdos diversos, assim como verificar diferentes versões sobre o mesmo assunto, visando a elaboração de pensamentos mais racionais e críticos. (COELHO, 2004).

Desse modo, verifica-se que a identidade histórica entre Biblioteconomia e Ciência da Informação já estabelecia certa sincronia no discurso de Naudé. Mesmo que Naudé tivesse 
consciência das dificuldades em aplicar o discurso de organização, difusão e acesso à informação para a população é inegável que este discurso auxiliou as gerações vindouras a pensar a possibilidade de liberdade de acesso à informação.

Com relação a Melvil Dewey foi um dos baluartes da Biblioteconomia mundial. As contribuições de Dewey, mesmo que "não intencionalmente" foram marcantes para a constituição do campo da Ciência da Informação, especialmente quando criou, em 1876, o Sistema de Classificação Bibliográfica que leva o seu nome (Classificação Decimal de Dewey ou simplesmente CDD), a Escola de Biblioteconomia em 1887, além de ter participado na criação da revista Library Journal e do Library Boreau com a perspectiva de normalizar os métodos biblioteconômicos. (CACALY et al., 1997).

As ações de Dewey contribuem para o advento da Ciência da Informação basicamente em dois contextos: o primeiro referente a uma nova propositura de organização bibliográfica do conhecimento, uma vez que a CDD se constitui em um amplo sistema de classificação do conhecimento que é utilizado até hoje em diversas bibliotecas espalhadas pelo mundo.

Pode-se dizer que Dewey insere a Biblioteconomia no contexto da modernidade, como uma área especializada na pretensão de criar coleções visando transformá-las em serviços. Dewey preocupa-se na utilidade do acervo da biblioteca e em sua propagação para a zona rural contribuindo para que a informação fosse mais acessível a população dos EUA e, por conseguinte, promovendo maior visibilidade social as bibliotecas. (TÁLAMO; SMIT, 2007).

Outra contribuição de Dewey está diretamente ligada ao campo das Ciências Cognitivas, com a qual a Ciência da Informação possui intrínseca relação. ${ }^{5}$ Esta contribuição se dá primeiramente no nível de colocar no contexto pragmático o significado lógico e técnico do conhecimento para que seja localizado e compreendido, como Dewey fez com a criação da CDD e, num segundo plano, pelo fato de que Dewey une lógica, técnica e cognição quando utiliza números arábicos e símbolos para representar o conhecimento humano.

Dessa forma, Dewey fomenta nos cientistas da informação do século XX, novas propostas e possibilidades de estudos para a organização do conhecimento. Obviamente que novos procedimentos para organização do conhecimento são amplamente necessários, tanto a partir da condição técnica de organização, disseminação, recuperação e uso da informação, quanto levando em consideração a condição cognitiva da compreensão de que é preciso a criação de meios que satisfaçam as necessidades dos usuários.

\footnotetext{
${ }^{5}$ Conforme Job (2008) a CI utiliza os pressupostos das Ciências Cognitivas nos estudos de usuários, no tratamento da informação e análise documental; nos estudos sobre categorização, indexação e recuperação da informação, nos estudos sobre leitura e o ato de ler; nos estudos sobre o ambiente organizacional, e no âmbito dos estudos sobre informação e no ensino da Biblioteconomia e Ciência da Informação.
} 
Vale ressaltar que o desenvolvimento da Biblioteconomia teve uma larga implementação pelo fato de que instituições dos EUA, tais como American Library Association (1876), National Association of State Libraries (1889), Medical Library Association (1898) e American Association of Law Libraries (1906), surgiram configurandose como um "movimento integrador e corporativista" (ROBREDO, 2003, p.43). Isso mostra que para construir a identidade de qualquer área do conhecimento, faz-se necessário um processo de institucionalização técnico-científico.

Finalmente, compreendendo o transcorrer histórico não apenas como uma narrativa e nem como uma sucessão de fatos, mas como um conjunto de contradições e paradoxos que são complementares ou conflitantes entre si, é preciso perceber que os estudos das diversas áreas do conhecimento possibilitaram o desenvolvimento de novos estudos, visando satisfazer as necessidades cotidianas da população.

No caso da Ciência da Informação, embora seja uma ciência do século XX, os estudiosos que iniciaram desde o início da Idade Moderna suas reflexões, como Naudé e Dewey, foram determinantes para estimular novas reflexões e ações nos intelectuais que o seguiram na cronologia da vida em torno da problemática da organização do conhecimento, tanto num plano técnico, quanto num plano cognitivo.

Além das contribuições de Naudé e Dewey, há ainda outros pesquisadores/estudos da Biblioteconomia que merecem ênfase, tais como: estudos quantitativos de produção bibliográfica, expostos por E. W. Hulme no British Patent Office Library, em 1922 e da distribuição bibliométrica elaborada por Samuel Clement Bradford e J. Lancaster Jones no Science Museum Library, em 1934; da teoria e prática da classificação explicitadas no livro The Organization of Knowledge and the System of the Sciences de Henry E. Bliss, em 1929; da aplicação de métodos de pesquisas sociais em estudos sobre bibliotecas publicados por Waples; dos sistemas de classificação e leis para bibliotecas, apresentados pelo bibliotecário indiano Shiyali R. Ranganathan (ROBREDO, 2003).

Ainda no final do século XIX (década de 1890), há uma disciplina que caminhou paralela a Biblioteconomia e foi crucial para o advento da Ciência da Informação: a Documentação. Vale considerar que Biblioteconomia e Documentação eram disciplinas idênticas até o final do século XIX.

Ortega (2004) admite que a Documentação esteve unida à Biblioteconomia desde o século XV até fins do século XIX, quando Otlet e La Fontaine desenvolveram a Documentação. Porém, a Documentação remonta sua origem da Bibliografia que, embora 
desenvolvida desde a antiguidade na Inglaterra, ganhou ênfase na Idade Moderna, quando Konrad Gesner, no final do século XV e o suíço Johann Tritheim, na metade do século XVI que tentou pela primeira vez construir uma bibliografia universal deram vazão para o crescimento da Bibliografia e o surgimento de diversos catálogos e códigos de catalogação nos séculos seguintes. A principal preocupação da Documentação estava no acesso à informação, nos mais diversos suportes documentais e em diferentes centros de informação (biblioteca, arquivo, museu), enquanto a Biblioteconomia estava desenvolvendo sua habilidade, em nível restrito, para proceder com a utilidade do livro e, em nível mais amplo, para indicar a atividade de gestão e organização de acervos de bibliotecas.

Otlet e La Fontaine buscaram subsídios institucionais, teórico-práticos e teóricobibliográficos para o desenvolvimento de suas pretensões na tentativa de focalizar o fenômeno social da informação. Para tanto, a tese de Otlet e La Fontaine forma norteadas por condições políticas e corporativas.

No discurso de Fayet-Scribe (2001) a criação do Instituto Internacional de Bibliografia (IIB) para gerenciar o Repertório Bibliográfico Universal (RBU), foi o primado básico para o desenvolvimento da Documentação. ${ }^{6}$ A pretensão do RBU era conceber uma síntese dos assuntos, desde a invenção da imprensa, por meio de fichar, de modo a promover uma rede conceitual que facilitasse e ampliasse o acesso à informação. Inicialmente, o RBU utilizava a CDD como instrumento de classificação. Porém, através de estudos baseados na CDD, Otlet e La Fontaine criaram a Classificação Decimal Universal, em 1905 (CDU). ${ }^{7}$ A autora assinala ainda que Otlet começou a utilizar o termo Documentação, em 1903, quando escreveu o artigo intitulado Les sciences bibliographiques et la documentation que discute sobre todo um processo relativo ao corpo organizacional, gerencial, de disseminação e acesso à informação.

Com efeito, é na obra Tratado de Documentação (Traité de Documentation) que a documentação otletiana ganha mais consistência epistemológica, de sorte que suas concepções teóricas e teleológicas mais relevantes são colocadas a tona. ${ }^{8}$

\footnotetext{
${ }^{6}$ O Instituto Internacional de Bibliografia, criado em 1895, transformou em Instituto Internacional de Documentação (IID) em 1931 e aferiu mais uma mudança em 1938 para Federação Internacional de Documentação que dura até hoje.

${ }^{7}$ A pretensão de Otlet e La Fontaine era promover uma nova identidade para a Documentação que se diferenciasse da Biblioteconomia. Essa nova caracterização identitária foi possível ao pensar uma atividade de organização, difusão e acesso à informação que pensasse as diversas possibilidades de acesso ao documento.

${ }^{8}$ Nesta obra, Otlet utiliza vários nomes para o termo Documentação, tais como Documentologia, Bibliologia e Ciências Bibliográficas, superando a noção de Biblioteconomia e Bibliografia de onde se presume que Otlet tomou base para criar a Documentação. (FAYET-SCRIBE, 2001).
} 
Otlet (1996, p. 10) estabelece alguns princípios para a Documentação consistindo em poder oferecer sobre todo tipo de fato e de conhecimento e informações documentadas a partir de quatro fundamentos:

$1^{\circ}$ o registro do pensamento humano e da realidade exterior em elementos de natureza material, ou seja, documentos; $2^{\circ}$ a conservação, circulação, atualização, catalografia, descrição e análise desses documentos; $3^{\circ}$ a elaboração, com a ajuda de documentos simples, dos documentos mais complexos, e com a ajuda dos documentos particulares, o conjunto desses documentos; $4^{\circ}$ em último grau, o registro dos dados cada vez mais completo, exato, preciso, simples, direto, rápido, sinótico, de forma simultaneamente analítica e sintética; seguindo um plano cada vez mais integral enciclopédico, universal e mundial

Diante dos princípios concebidos por Otlet é possível identificar uma forte relação com o discurso da Ciência da Informação. A relação pode ser pensada em diversos níveis: o primeiro é referente a preocupação com o acesso à informação. Para tanto, a noção de acesso, seja na Documentação otletiana ou na Ciência da Informação presume os fundamentos deliberados no Tratado de Documentação; em segundo plano, ocorre o fato de que muitas expressões técnicas utilizadas por Otlet relativas a informação e a documentação passaram a ser utilizadas com freqüência na Ciência da Informação, tais como: produção, registro, estatística, conservação, utilização, compilação, síntese.

Isso significa dizer que Otlet procurou incessantemente sintetizar a informação, visando tornar o acesso mais facilitado e rápido, assim como tornando a informação mais confiável; o terceiro aspecto é referente a estruturação de condições para que as informações pudessem ser extraídas do documento, transcritas em fichas e correlacionadas com assuntos semelhantes, com vistas a formar uma rede conceitual (rede de informações) dinâmica, de acordo com a necessidade dos usuários.

Otlet possuía uma visão de mundo consistente, pois em seus estudos conseguiu agregar construtos teóricos e práticos; bibliográficos e documentais; científicos e técnicos; ontológicos e epistemológicos; políticos e cotidianos.

Ortega (2004, p. 7) afirma sobre a tentativa de rompimento de Otlet com o racionalismo moderno de Dewey e sua forte percepção política da realidade social e informacional:

Otlet fazia críticas às bibliotecas por conta das políticas de seleção (advindas do princípio jesuítico) e da resistência às inovações técnicas e à prestação de serviços de informação. Além disso, o projeto de Otlet pretendia armazenar a representação das unidades de todo o conhecimento humano em um único local; era um projeto universalista e concebido como uma ação para a promoção da paz mundial, de onde se pode considerar que as bases da Documentação eram técnicas, mas também fortemente políticas. 
Assim, é possível identificar que Otlet constituiu uma identidade de projeto para a Documentação que segundo Castells (2008) significa o posicionamento dos atores sociais que buscam construir uma nova identidade a fim de promover um novo posicionamento na sociedade e modificações na estrutura social. A identidade de projeto (CASTELLS, 2008) se justifica para Otlet por alguns aspectos cruciais:

a) primeiramente o fato de que Otlet foi um propositor de uma nova identidade para os estudos sobre documentos e informação, pois como nos revela Mattelart (2002, p. 233) Otlet estudou "as questões concernentes ao Livro e à organização sistemática da Documentação em bases internacionais e universais".

b) foi modificador das estruturas sociais no que tange as noções sobre informação;

c) previu o desenvolvimento das tecnologias, como os sistemas de hipertexto e hipermídia (RAYWARD, 1997).

Não é exagero afirmar, inclusive que Otlet forneceu as bases para o advento da Ciência da Informação, conforme afirma Figueiredo (1996, p. 16):

O [Tratado] de Documentação [...] é, talvez, [...] a primeira sistemática e moderna discussão dos problemas gerais da organização da informação. $O$ termo documentação é um neologismo, criado por Otlet, para designar o que hoje em dia tendemos a chamar de armazenamento e recuperação da informação. De fato, "não é exagero declarar-se que o tratado foi um dos primeiros textos de Ciência da Informação..." Propõe novos tipos de sistemas mecânicos integrados para o manejo da informação, os quais teriam ainda de ser inventados e transformariam o meio ambiente e as práticas dos pesquisadores.

Desse modo, compreende-se que Otlet desenvolve sustentações teóricas, epistemológicas e ontológicas para a Ciência da Informação. Teóricas e epistemológicas em virtude do seu livro Tratado de Documentação propor um processo efetivo de discussão sobre os rumos da informação, difusão e compartilhamento, especialmente através de uma rede. Ontológicas pelo fato de que Otlet atenta para o documento e a informação como fenômenos que precisam ser representados.

Para tanto, dependem de várias questões, dentre as quais podem ser destacadas: conhecimento sobre a linguagem (objetividade lingüística); conhecimento sobre a realidade objetiva que envolve espaço, tempo e outras variantes e o conhecimento sobre a realidade subjetiva que está relacionada a visão do Eu e do outro referentes a visão de mundo. A junção da realidade objetiva e da mente permite uma compreensão mais efetiva do mundo, assim como possibilita uma noção mais completa da representação documentária e informacional. (DUCHEYNE, 2005). 
Observa-se que Otlet oferece as bases para o estabelecimento da Ciência da Informação quando focaliza a informação como fenômeno social que existe e é tratada na Biblioteconomia, Arquivologia e Museologia, mas gera uma confusão epistemológica quando tenta afirmar que é objeto apenas de uma nova disciplina chamada Documentação. Entende-se que essa afirmação da Documentação como campo essencial para pensar a informação e seus construtos organizacionais em detrimento da Biblioteconomia, da Arquivologia e da Museologia está relacionada a uma visão política eminentemente corporativista de Otlet e La Fontaine.

Para resumir os contributos de Naudé, Dewey e Otlet no que concerne ao surgimento da Ciência da Informação o quadro a seguir ilustra o processo:

\begin{tabular}{|c|c|c|c|}
\hline $\begin{array}{c}\text { Linha do } \\
\text { tempo }\end{array}$ & Exemplo & Função social da informação & $\begin{array}{l}\text { Característica } \\
\text { predominante }\end{array}$ \\
\hline $\begin{array}{l}\text { Até o final } \\
\text { do século } \\
\text { XIX }\end{array}$ & $\begin{array}{c}\text { Gabriel Naudé (1600-1653) } \\
\text { - Bibliotecário-erudito. Organiza } \\
\text { bibliotecas da classe dominante e } \\
\text { concebe a biblioteca pública } \\
\text { - a diversidade de correntes de } \\
\text { pensamento deve estar presente na } \\
\text { biblioteca }\end{array}$ & $\begin{array}{l}\text { - a informação reforça o poder } \\
\text { - a biblioteca como espaço } \\
\text { privilegiado da erudição e da } \\
\text { liberdade de expressão. } \\
\text { A pessoa e seu poder. }\end{array}$ & $\begin{array}{c}\text { ACESSO } \\
\text { ERUDIÇÃO } \\
\text { MODERNIDADE }\end{array}$ \\
\hline $\begin{array}{c}\text { Final do } \\
\text { século } \\
\text { XIX e } \\
\text { início do } \\
\text { século XX }\end{array}$ & $\begin{array}{c}\text { Melvil Dewey (1851-1931) } \\
\text { Biblioteconomia moderna } \\
\text { - serviços bibliotecários para } \\
\text { usuários segmentados } \\
\text { - busca pela praticidade } \\
\text { - institucionalização da } \\
\text { Biblioteconomia (ensino e } \\
\text { associação e profissional) }\end{array}$ & $\begin{array}{l}\text { - a informação como meio } \\
\text { para o desenvolvimento } \\
\text { - a biblioteca como adjuvante } \\
\text { da ciência moderna } \\
\text { A pessoa e suas necessidades } \\
\text { informacionais }\end{array}$ & $\begin{array}{l}\text { UTILITARISMO } \\
\text { COLEÇÃO } \\
\text { SERVIÇO } \\
\text { RACIONALIDADE } \\
\text { MODERNA }\end{array}$ \\
\hline $\begin{array}{c}\text { Entre- } \\
\text { guerras } \\
1934\end{array}$ & $\begin{array}{c}\text { Paul Otlet (1868-1944) } \\
\text { Documentação } \\
\text { - a organização da informação } \\
\text { como constituição de uma rede } \\
\text { - ênfase na informação em } \\
\text { detrimento do documento }\end{array}$ & $\begin{array}{c}\text { - a informação como } \\
\text { finalidade em si: a informação } \\
\text { gera condições para provocar a } \\
\text { paz } \\
\text { A necessidade informacional } \\
\text { da sociedade }\end{array}$ & $\begin{array}{c}\text { ACESSO } \\
\text { e } \\
\text { RECEPÇAO } \\
\text { ADAPTABILIDADE } \\
\text { A NECESSIDADES } \\
\text { CAMBIANTES } \\
\text { MODERNIDADE } \\
\text { e } \\
\text { PÓS- } \\
\text { MODERNIDADE } \\
\end{array}$ \\
\hline
\end{tabular}

Quadro 1: Ideias de Gabriel Naudé, Melvil Dewey e Paul Otlet.

Fonte: Adaptado do texto de Tálamo e Smit (2007).

Entretanto, pode-se verificar um amplo conflito entre a Documentação e a Biblioteconomia a partir de interesses políticos e corporativos. A primeira, com uma característica essencialmente advinda da Europa, uma vez que Otlet e La Fontaine eram 
belgas e a segunda que apresentava grande representatividade nos EUA com uma tonalidade marcadamente nacionalista, principalmente através da Escola de Chicago. ${ }^{9}$

Percebe-se certa resistência dos documentalistas europeus em agregar práticas biblioteconômicas e muita resistência dos estudiosos estadunidenses em agregar estudos mais cientificistas dos documentalistas europeus. Isso significa dizer que a origem da Ciência da Informação torna-se mais obscura em face da fragmentação dos estudos com Biblioteconomia e Documentação, visto que os interesses políticos e corporativos podem interferir nos avanços da Ciência da Informação. López Yepes (1995) afirma que o conceito de Documentação empregado por Paul Otlet foi se fragmentando em virtude da polêmica Biblioteconomia versus Documentação.

Pode-se dizer que a polêmica entre Biblioteconomia e Documentação proporcionou a ideia de uma identidade contrastiva que, de certo modo, fragmentou a construção da identidade da Ciência da Informação. Comumente este tipo de identidade é utilizado no contexto étnico quando um grupo pretende superar o outro ou quando um grupo nega a identidade do outro em um procedimento recíproco. No caso da Biblioteconomia e da Documentação ocorre a identidade contrastiva a partir do momento em que ocorre uma supervalorização da identidade biblioteconômica estadunidense e de uma identidade da documentação européia.

Inclusive, o pesquisador dos EUA, mas com forte tendência a literatura documentalista européia Buckland (1996) entende que se os EUA tivessem retomado os estudos dos primeiros documentalistas europeus e dos estudos e propostas dos pioneiros estadunidenses que atuaram em fins do século XIX os estudos teriam sido mais acurados, eficazes e com custos até mais baratos. Quando a Ciência da Informação foi criada nos EUA, muitos bibliotecários sentiram-se ameaçados considerando que haveria uma espécie de competição entre Biblioteconomia e Ciência da Informação. O advento da Ciência da Informação parte de um arrazoado técnico-científico carente de objetivos, finalidades, métodos, além de noção escassa de tecnologia para construção identitária da área.

Ressalta-se a importância da Biblioteconomia e principalmente da Documentação para o surgimento da CI. Vale destacar que a Documentação foi um importante expoente para alavancar o entendimento sobre informação, bem como promoveu ideias inovadoras sobre tecnologia aplicada aos centros de informação e suportes documentais.

\footnotetext{
9 Vale ressaltar que com as Guerras mundiais, a Europa ficou arrasada e, embora tenha produzido consideravelmente em termos de documentação e informação, os recursos eram escassos para difusão e implementação dos estudos em outros países, o que dificultou um a concepção de um processo de identidade partilhada. (HALL, 1999).
} 
Acredita-se que estes se constituem essencialmente como os antecessores sociais e científicos que direta e indiretamente contribuíram para o advento da Ciência da Informação, o que provoca a manifestação de um dado fenômeno, causa, motivo e procedência.

\section{FATORES QUE CONTRIBUÍRAM PARA O ADVENTO DA CIÊNCIA DA INFORMAÇÃO: IDENTIDADE PARTILHADA E INSTITUCIONAL}

Partindo para a segunda estrutura relativa aos acontecimentos institucionais, técnicos e científicos que marcadamente promoveram a origem e o caminhar da Ciência da Informação (o surgimento ou início de alguma coisa e princípio, começo e ascendência).

O primeiro fator envolve um período muito conturbado na história da humanidade que é a II Guerra Mundial (1939-1945). Vale destacar que no período da II Guerra estava ocorrendo a explosão informacional que demandou muitos problemas de informação e estudos para solução desses problemas.

Vannevar Bush, um respeitado cientista do Instituto de Tecnologia de Massachusetts (MIT) e chefe do esforço científico dos EUA durante a Segunda Guerra Mundial, despontava como um estudioso voltado para resolver problemas de organização estratégia da informação e recuperação de informação. É com um artigo intitulado As me may think, elaborado em 1939, mas somente publicado em 1945 que Bush apresenta sua mais famosa e, talvez, mais eficiente maneira de resolver o problema relativo a organização e gerenciamento da informação. ${ }^{10}$ Bush, inicialmente identifica problemas relativos a explosão informacional e propõe a criação de uma máquina chamada Memex que previa a possibilidade de associar ideias. (BUSH, 1987). ${ }^{11}$

Percebe-se que Bush contribuiu de várias formas para o advento da Ciência da Informação implementando marcas identitárias que até hoje são discutidas e estudadas.

A primeira delas implica dizer que para a atuação da Ciência da Informação é de crucial relevância o uso das tecnologias de informação e comunicação, pois favorecem amplamente o processo de organização, difusão, acesso e gerenciamento da informação, além do que condiciona a Ciência da Informação a atuar a partir de qualquer suporte documental.

\footnotetext{
${ }^{10}$ O artigo de Bush apareceu primeiro em 1939, em uma carta ao editor da revista Fortune, teve sua histórica versão no periódico Atlantic Monthly e posteriormente a revista Life fez várias observações e chamadas sobre o trabalho. (BARRETO, 2002, p. 3).

${ }^{11} \mathrm{O}$ Memex não chegou a ser construído, mas os pressupostos que deliberaram sua idealização inspiraram diversos pesquisadores e cientistas da atualidade. (FERNEDA, 2003).
} 
A segunda está relacionada as intrínsecas relações entre Ciência da Informação e outras áreas do conhecimento que surgiram e se desenvolveram contiguamente, como é o caso da Ciência da Computação, Ciências Cognitivas, especialmente a Inteligência Artificial (IA), disciplina a qual Bush também contribuiu para o seu advento.

A terceira é que Bush valorizou a informação de tal modo que contribuiu para inseri-la no rol de instrumentos relevantes para a sociedade, pois governos e empresas privadas procuraram desenvolver programas, políticas e projetos para gerenciar os fluxos de informação e controlar a explosão informacional, inicialmente, com o olhar voltado para a informação científica e tecnológica e, logo em seguida, para a informação em diversos outros campos. (SARACEVIC, 1996).

A quarta contribuição é conseqüência da anterior, pois com políticas governamentais e empresariais, a informação foi conquistando maior relevância no âmbito da sociedade promovendo melhores perspectivas de acesso à informação.

A qualidade das contribuições de Bush para o advento da Ciência da Informação está em sua diversidade. Tanto é possível afirmar que Bush contribuiu para originar e desenvolver a Ciência da Informação em seu contexto técnico e epistemológico (como ciência aplicada), bem como contribuiu para o desenvolvimento cotidiano da Ciência da Informação através da valorização da informação como instrumento de apoio ao aprendizado da sociedade, em termos mais específicos, os usuários.

É preciso ponderar uma questão conforme os dois pontos destacados no presente trabalho sobre as origens da Ciência da Informação:

a) antecessores sociais e científicos que direta e indiretamente contribuíram para o advento da Ciência da Informação ,o que provoca a manifestação de um dado fenômeno, causa, motivo e procedência;

b) acontecimentos institucionais, técnicos e científicos que marcadamente promoveram o caminhar da Ciência da Informação. qual seja,o surgimento ou início de alguma coisa e princípio, começo e ascendência.

Compreende-se, de acordo com a reflexão concebida no presente trabalho, que o estudioso que promoveu as bases para o advento da Ciência da Informação foi Paul Otlet, sendo o principal precursor do primeiro ponto, enquanto Vannevar Bush foi o precursor do segundo ponto, a institucionalização da Ciência da Informação como área do conhecimento. Em outras palavras, é inegável que as contribuições teóricas, epistemológicas e ontológicas de Otlet promoveram os sustentáculos para o advento da Ciência da Informação e as 
contribuições de Bush promoveram sustentáculos para formalização da área como campo do conhecimento.

Observa-se que boa parte do discurso de Bush se constitui como marcas identitárias da CI, tais como: informação em ciência e tecnologia; armazenagem a recuperação da informação; construção teórica de condições para representação, processamento, armazenagem e recuperação de informação.

Além de suas contribuições técnico-científicas e cotidianas no contexto da informação, Bush apresenta outro contributo que, em tese, favorece o fortalecimento da identidade da Ciência da Informação: um contributo político e cultural para a Ciência da Informação. Em outras palavras, Bush auxilia de forma subjacente para que a Ciência da Informação, embora oriunda dos EUA não apresente apenas uma realidade continental e sim global, visando constituir uma unidade na caracterização identitária da área.

Porém, é preciso abrir um parêntese para falar sobre as dificuldades de estabelecer uma configuração identitária da Ciência da Informação. Pode-se considerar ao menos em termos culturais e políticos, que a Ciência da Informação tentou apresentar uma unidade no que tange a sua aceitação em nível global. Um problema que dificultou a inserção da Ciência da Informação e sua compreensão é relativo a uma propositura terminológico-epistemológica, pois é inegável que os inúmeros termos (disciplinas) que designaram o surgimento da Ciência da Informação são eminentemente complexos e diversificados para se pensar uma efetiva consistência identitária.

Blaise Cronin (2008) entende que os conceitos robustos que compõem núcleo intelectual do nosso campo (por exemplo, conhecimento, informação, representação de comunicação) não são de propriedade da Ciência da Informação, nem susceptível de serem montados em uma proposta consistente, sem adição criteriosa de perspectivas e abordagens adotadas das disciplinas estabelecidas, como a ciência da computação, lingüística, filosofia, psicologia e sociologia, bem como dos campos mais recentes, como a ciência cognitiva e a interação homem-computador.

Como conseqüência desse conjunto de campos robustos que estão associados a Ciência da Informação fica evidente também a construção de conceitos variados para este campo do conhecimento. Conforme Zins (2011, p. 155) “o próprio conceito de Ciência da Informação não apresenta uniformidade, pois "O campo parece seguir diferentes abordagens e tradições; por exemplo: abordagens objetivas versus abordagens cognitivas, a tradição da 
biblioteca versus a tradição da documentação versus a tradição da computação, e assim por diante".

Ortega (2009, p. 26) confirma a dificuldade em estabelecer a configuração identitária quando afirma que:

Dado o provável uso inicial da expressão 'informação e documentação', por Otlet, em 1905, supomos que desde então várias expressões compostas foram e são utilizadas pela área, levando a dificuldades de construção identitária, como: Bibliografia e Documentação, Informação e Documentação, Biblioteconomia e Documentação, Ciência da Informação e Documentação, Biblioteconomia e Ciência da Informação, Biblioteconomia e Gestão da Informação.

Isso significa dizer que existe certo modismo na Ciência da Informação e em suas disciplinas, como a Biblioteconomia e a Documentação no que tange a utilização e aplicação terminológica e epistemológica. A diversidade de terminologias utilizadas interferiu no processo de construção de uma consistência epistemológica da Ciência da Informação, embora seja inegável que as terminologias utilizadas pelos estudiosos no final do século XIX e início do século XX tinham valorizações relativamente regionalizadas (continentais) e restritivas no trato com a informação, o que interferia no pensamento em uma percepção cientificamente globalizado sobre a informação. ${ }^{12}$

De certo modo, a Ciência da Informação vem com o propósito de condensar os estudos científicos sobre a informação, assim como contribuir para aprimorar disciplinas como a Documentação, a Biblioteconomia, a Arquivologia, a Museologia e a Gestão da Informação em seus tratos específicos com a informação e os documentos, de acordo com as necessidades científicas, disciplinares, profissionais e cotidianas de cada região, país ou continente.

Lembrando as ações de Bush é possível afirmar que seus resultados para o advento da Ciência da Informação em nível global pareceram ser promissores, conforme o discurso de Barreto (2002, p. 3):

As idéias de Bush provocaram tamanho frisson na época, que foram parar em Londres. Em 1946, um ano após o término da Segunda Guerra, foi realizada em Londres a Royal Empire Society Scientific Conference, onde se discutiu muito pouco sobre informação, mas que levou à realização, em 1948, da Royal Society Scientific Information Conference. Cerca de 340 cientistas e documentalistas de todo o mundo compareceram a essa Conferência, que durou dez dias úteis. Os seus Proceedings (1958) têm 723 páginas, com dois volumes e quatro seções: I - as publicações originais, II - serviços de resumo, III - indexação e outros serviços de Biblioteca, IV - revisões de literatura e relatórios anuais. A publicação dos proceedings levou dez anos para sair e foi editada nos Estados Unidos. Os cientistas de quase todas as áreas tinham propostas para resolver os problemas da gestão da informação, mas para não perder o status acadêmico, a nova área foi criada com o nome de: ciência da

${ }^{12}$ Verifica-se que essa proliferação de termos, como Biblioteconomia e Documentação é marca de uma visão política e corporativista dos estudiosos. 
informação. Os resultados da Conferência, apesar das 723 páginas, ficaram muito perto dos problemas apontados por Vannevar Bush.

Diante do discurso de Barreto é possível identificar um indício de identidade partilhada para a criação da Ciência da Informação entre os EUA e o continente europeu. Essa identidade partilhada consta de um compartilhamento integrado entre nações distantes a partir de seus fluxos culturais e seus serviços, imagens e mensagens (HALL, 1999).

Em termos culturais e científicos, estudiosos de todo o mundo, principalmente dos EUA e da Europa compartilharam seus entendimentos acerca de propostas para organização, armazenagem e recuperação de informação, visando compartilhar seus fluxos culturais para resolver problemas de informação.

Embora boa parte dos estudiosos da Conferência tenha pensado em resolver problemas específicos de gestão da informação, é interessante atestar o contexto de uma identidade partilhada em face da proposta de criar uma Ciência da Informação para adquirir um status acadêmico mais efetivo. Isto implica dizer que cada país ou continente pode ter apresentado realidades específicas no que tange à construção do campo científico da Ciência da Informação, mas o despertar da área foi basicamente o mesmo em nível global.

Saracevic (1996, p. 43) confirma essa universalidade da Ciência da Informação quando afirma que:

\begin{abstract}
Apesar de os Estados Unidos desempenharem o papel mais proeminente no desenvolvimento da CI (como fizeram com a ciência da computação), nem os problemas informacionais nem a CI são americanos em sua natureza. Eles são internacionais ou globais. Não existe mais uma "CI americana", assim como não existem ciência da computação ou ciência cognitiva americanas. A evolução da CI nos vários países ou regiões acompanhou diferentes acontecimentos ou prioridades distintas, mas a justificativa e os conceitos básicos são os mesmos globalmente. $\mathrm{O}$ despertar da CI foi o mesmo em todo o mundo.
\end{abstract}

Pode-se atestar que cada país teve suas peculiaridades e amadurecimentos científicos diferentes. Mas a essência da Ciência da Informação em lidar com os problemas informacionais apresentava uma mentalidade universalizada. Um exemplo dessa universalidade que ficou latente em boa parte do mundo foi a discussão entre Ciência da Informação e Biblioteconomia.

Limiarmente, a ideia da Ciência da Informação não agradou a boa parte dos bibliotecários em virtude de que muitos consideravam que a tônica no advento de uma nova ciência seria uma espécie de substituição de uma disciplina (Biblioteconomia) por outra (Ciência da Informação). ${ }^{13}$

${ }^{13}$ Assim como para Otlet e otletianos a Biblioteconomia não agradava à Documentação. 
Essa discussão acadêmica nos países em que a Ciência da Informação amadureceu mais rapidamente (EUA, por exemplo) durou aproximadamente até o final da década de 70 e início da década de 80. Em outros países onde a Ciência da Informação demorou mais a se desenvolver, a discussão com a Biblioteconomia, a Arquivologia e a Museologia perdura até hoje significando dizer que o momento histórico pode ser diferenciado, mas o contexto informacional possui uma semelhança eminentemente globalizada. Essa discussão tem uma inserção fortemente ligada ao contexto corporativo e político. No Brasil, por exemplo, já no século XXI, a Arquivologia, por interesses políticos e corporativos reivindicou sua retirada do rol de disciplinas incluídas no campo da Ciência da Informação.

Assim como a Biblioteconomia precisou de uma institucionalidade para desenvolver sua identidade através das associações bibliotecárias, a Ciência da Informação também seguiu um estilo semelhante.

Em 1949, Jason Farradane, J. Bernal e outros criaram o Institute for Information Scientists (Instituto de Cientistas da Informação), com a proposta de reunir os estudiosos e agregar as novas ideias que estavam constituindo a Ciência da Informação. Atualmente, o Instituto se reuniu com a Documentação e a Biblioteconomia e está agregado a Chartered Institute of Library and Information Professionals (Instituto de Profissionais de Bibliotecas e Informação). Ainda destaca-se a criação, em 1952, pelo grupo dos cientistas da informação o Classification Research Group, que pretendia propor novas teorias para armazenar e recuperar a informação. Os mesmos criadores do Institute for Information Scientists fundaram sob o comando de Jason Farradane o primeiro programa de pós-graduação em Ciência da Informação na The City University, anteriormente chamada de Northampton College of High Technology, localizado na Cidade de Londres, na Inglaterra. (BARRETO, 2008).

Verifica-se que os pesquisadores que emergiram na criação do Institute for Information Scientists estavam determinados a desenvolver uma área cientificamente encaminhada para lidar com os problemas de informação. A criação de um curso de pósgraduação em Ciência da Informação é um dos principais primados para conceber um construto de identidade científica da área.

Outrossim, é pertinente destacar algumas teorias que tratam sobre informação e contribuíram para o advento da Ciência da Informação. Destaca-se a Teoria Matemática da Comunicação (conhecida também como Teoria Matemática da Informação ou simplesmente Teoria da Informação) e a Teoria Sistêmica da Informação. 
A Teoria Matemática da Comunicação foi apresentada em 1948 e publicada em 1949, o que significa dizer que coincide com o momento em que a Ciência da Informação tenta institucionalizar seus primeiros passos com a Royal Society Scientific Information Conference. É possível afirmar que Shannon e Weaver procuram analisar o processo de comunicação. Para tanto, apresentam um enunciado científico que tem como enfoque central a informação. Shannon e Weaver ponderam o desenrolar da informação e de suas fontes de transmissões.

Conforme afirma Araújo (2009, p. 193) Shannon e Weaver reconhecem que o processo de comunicação envolve três problemas:

$\mathrm{O}$ primeiro trata dos problemas técnicos, relativos ao transporte físico da materialidade que compõe a informação (como, por exemplo, o volume do som numa conversa ou a qualidade da impressão em um papel). O segundo nível se refere aos problemas semânticos, isto é, se relaciona com a atribuição de significado. Enquanto o primeiro nível envolve apenas uma operação mecânica (reconhecer as letras num papel, captar os sons de uma fala), o segundo se relaciona a uma operação mental específica, a de depreender, de determinada materialidade (sonora, visual, etc), um sentido, que pode se dar de maneira conotativa ou denotativa, literal ou irônica, metafórica, etc. O terceiro nível é o pragmático, relaciona-se com a eficácia.

Shannon e Weaver priorizam o processo de comunicação a partir do seu contexto físico e com a eficácia da transmissão. Isso implica dizer que os autores priorizam a noção de linearidade e objetividade no processo comunicacional em detrimento da subjetividade e das diversas formas de interpretação na comunicação. Isto é, a comunicação reside no fato de uma fonte que depende de um transmissor que, por meio de um canal, envia informação a um receptor. Este canal pode ser considerado como um relevante fator para mediação e eficácia do processo comunicacional.

A vantagem de priorizar a linearidade e objetividade da informação é que permitiu a construção objetiva de um enunciado científico acerca da informação. Os autores entendem a informação como um elemento passível a incerteza, pois o seu entendimento é relativo as possibilidades de como se poderia informar.

Para esclarecer melhor esse processo de comunicação Shannon e Weaver (1949) desenvolveram um esquema demonstrando como o processo comunicacional é concebido e a importância central da informação.

No que concerne a Teoria Sistêmica da Informação flui basicamente no mesmo período da Teoria Matemática da Comunicação. Em 1948, Wiener publica artigo sobre 
Cibernética exercendo grande influência na Ciência da Informação. ${ }^{14}$ A teoria supramencionada é originária da Biologia e pensa o estudo de qualquer fenômeno em uma tessitura funcional. Isto quer dizer que um determinado objeto de uma estrutura exerce o seu papel de forma específica contribuindo para a construção do todo. Por exemplo, um sistema de bibliotecas universitárias é constituído de um conjunto de bibliotecas específicas para cada área do conhecimento ou centros universitários (Centro da Saúde, Direito, Ciências Humanas, Ciências Agrárias, Centro de Tecnologia, Ciências Exatas, etc.) e cada biblioteca contribui, a partir da sua realidade específica, para o crescimento de todo o sistema de bibliotecas universitárias.

Assim, entende-se que a Teoria Sistêmica da Informação prima pelo caráter cíclico (circular) do fenômeno, uma vez que em uma estrutura, sempre haverá elementos que acabam e outros que surgem proporcionando o caráter cíclico da estrutura, o que difere das teorias que partem da Física e da Matemática (Teoria Matemática da Comunicação, Recuperação de Informação, entre outras) que valorizam o caráter linear das estruturas.

Shera (1970) acredita que a Teoria Sistêmica da Informação teve uma influência direta para a origem da Ciência da Informação que se configura na teoria funcionalista que envolve a ação da informação na sociedade. Bibliotecas, arquivos, museus e outros centros de informação devem ter um papel específico satisfazendo setores específicos da sociedade. Por exemplo, uma biblioteca pública deve ter suas estruturas e ações bem delineadas através da preservação da memória e da cultura, de ações educativas, visando satisfazer os diversos segmentos da sociedade (pode ser entendido aqui como comunidades de usuários).

Outra influência que a Teoria Sistêmica da Informação exerceu sobre a Ciência da Informação está ligada aos sistemas de informação. Os sistemas de informação são sempre pensados a partir da lógica dos processos de entrada (entrada de dados, com a aquisição de itens informacionais, a seleção destes itens para a composição de determinado acervo), de processamento (os itens informacionais que dão entrada num sistema de informação precisam ser descritos, catalogados, classificados, indexados) e de saída (pelo acesso aos itens informacionais por parte dos usuários, na forma de disseminação, entrega da informação, empréstimo, etc). (ARAÚJO, 2009, p. 196).

Calvin Mooers criou, em 1951, o termo Retrieval Information (Recuperação da Informação) considerando que a recuperação de informação engloba os aspectos intelectuais

\footnotetext{
${ }^{14}$ Embora os efeitos da Teoria Sistêmica da Informação tenham impacto sobre a CI em 1948, a sua existência data da década de 1930 com Bertalanffy.
} 
da descrição da informação e de sua especificação para a busca, bem como qualquer sistema, técnica ou máquina que são utilizadas para realizar a operação. (FERNEDA, 2003).

A Recuperação de Informação apresenta um contributo para a Ciência da Informação que se configura em uma condição pertinente para a área até os dias de hoje: procedimentos de representação da informação para uma busca eficiente e eficaz em sistemas (uma espécie de concepção tecnológica para a Ciência da Informação). Isso significa dizer que Recuperação de Informação e Ciência da Informação caminharam lado a lado desde o surgimento para resolver problemas de informação conjuntamente.

Mooers publica o artigo intitulado "Law or, Why Some Retrieval Systems Are Used and Others Are Not" (Lei ou, por que alguns sistemas de recuperação são usados e outros não são) apresentando um princípio que ficou conhecido como Lei de Mooers onde afirma que: um sistema de recuperação de informações terá a tendência de não ser usado se é mais irritante e problemático para um usuário obter a informação do que não obtê-la. Mooers não está falando do sistema de recuperação de informação em si (sua funcionalidade e operacionalidade). O seu discurso é mais complexo do que o atrelamento ao sistema. A principal preocupação de Mooers é saber como o sistema processa a informação e como o usuário irá utilizá-la, uma vez que o usuário, para conceber relevância a informação, precisa lê-la e entendê-la e esses procedimentos podem interferir substancialmente nos processos de busca realizados pelo usuário se o sistema não apresenta clareza na recuperação das informações. (AUSTIN, 2001).

Assim, Mooers prioriza a díade sistema-usuário como faces complementares em que o primeiro processa a informação e o segundo definirá sua relevância de acordo com os seus mecanismos de busca e de acesso aos documentos. Como Mooers atenta para a utilidade da informação que satisfaça o usuário e, por conseguinte, que resolva problemas de informação, infere-se a sua relevância para os estudos em Ciência da Informação, pois há uma associação direta deste campo do conhecimento com as Ciências da Computação, Ciências Cognitivas. ${ }^{15}$

O fato é que um sistema de recuperação de informação (SRI) reúne condições para representar a informação e recuperar dados daquele documento, visando fornecer subsídios para que o usuário tenha condições mais efetivas de interpretar aquilo que considere mais relevante, mas o sistema em si não preconiza um "ritual tecnológico" de recuperação de informação e sim dados ou referências de um documento.

\footnotetext{
${ }^{15}$ Vale ressaltar de acordo com Cronin (2008) que outros autores também se destacaram no desenvolvimento dos estudos sobre recuperação de informação, tais como: Cranfield (década de 1960); David Ellis com a criação do Text Retrieval Conference (TREC (década de 1990), entre outros.
} 
Daí, o motivo pelo qual o termo recuperação de informação é tão questionado em termos terminológicos causando certa crise de identidade. Em que pese essa crise de identidade terminológica, obviamente que não interfere na relevância da Recuperação de Informação para estudar problemas tecnológicos relativos a informação.

Mas é necessária uma interpretação mais precisa das propostas de Mooers e dos modelos e sistemas para recuperação de informação desenvolvidos pelos renomados estudiosos. Essa interpretação e revisão da Recuperação de Informação permite avaliar a necessidade de mecanismos sócio-cognitivos para uma pensar uma recuperação de informação que priorize as necessidades dos usuários e não simplesmente a estruturação de sistemas e/ou modelos para recuperação de informação em si. ${ }^{16}$

Todo esse discurso das décadas de 40 e 50, relativos ao advento da Ciência da Informação, das Ciências Cognitivas, da Computação (em caráter particular da Recuperação de Informação), além dos eventos institucionais para estudar a informação e criar uma área a ser consolidada cientificamente não só deram origem a Ciência da Informação, como foram fatores precípuos de seu desenvolvimento.

A Recuperação de Informação, inclusive, estabelece uma relação com a Bibliometria e outras técnicas métricas da informação (Cienciometria, Webometria e Infometria) que influenciaram muito no desenvolvimento da Ciência da Informação. As relações entre Recuperação de Informação e as técnicas métricas de informação se dão em vários níveis: a primeira é concernente aos estudos de citações e co-citação para recuperação de informação; a segunda é referente a ação das técnicas infométricas para determinar o desempenho dos sistemas de recuperação da informação; a terceira é avaliar a circulação e uso de documentos em um centro de documentação; a quarta é medir o grau e padrões de colaboração entre autores e a quinta é avaliar os aspectos estatísticos da linguagem, das palavras e das frases. (VANTI, 2002).

Há ainda outro aspecto para caracterizar a origem da Ciência da Informação. É muito comum o discurso de que o início da CI ocorre, de fato, em 1962 na Georgia Institute of Technology no Estado da Georgia, nos EUA a partir da Conferência denominada Conferences on training science information specialists (Conferências sobre a formação de especialistas de ciência da informação).

\footnotetext{
${ }^{16}$ Certamente o advento do paradigma social desenvolvido por Birger Hjørland e Hanne Albrechtsen é fundamental para refletir sobre uma recuperação de informação que priorize as necessidades do usuário. (CAPURRO, 2003).
} 
É inegável a importância da Conferences on training science information specialists, haja vista que buscou a capacitação dos componentes da área, assim como procurou alavancar a Ciência da Informação nos EUA. Entretanto, é preciso refletir que as bases teóricocientíficas para a construção de uma Ciência da Informação em nível global estavam relativamente fincadas, desde os contributos dos bibliotecários e documentalistas do final do século XIX e início do século XX, até as proposições de Vannevar Bush e as Teorias Matemática e Sistêmica da Informação, entre outros atributos discutidos neste trabalho.

Ainda há outros acontecimentos relevantes para o advento da Ciência da Informação que valorizaram o processo de inserção científica da área em termos globais, tais como: a publicação do American Documentation, nos Estados Unidos, e do Nachrichten für Dokumentation, na Alemanha, ambos em 1950 e até hoje relevantes periódicos da área. $\mathrm{Na}$ URSS, o principal indício é a criação, em 1952, do VINITI - Vserossiisky Institut Nauchnoi i Tekhnicheskoi Informatsii (All-Union Institute for Scientific and Technical Information), vinculado à Academia de Ciências da Rússia, com a missão de prover informação para cientistas e especialistas nas ciências técnicas e naturais. (FREIRE, 2006, p. 11).

Vale ressaltar a importância da antiga União das Repúblicas Socialistas Soviéticas (URSS) na construção do VINITI e da Ciência da Informação, ou melhor, dizendo, Informatika para a Ciência da Informação em nível global. A figura de Alexander Ivanovich Mikhailov foi fundamental para construir a Informatika como disciplina que estuda as propriedades da informação científica. ${ }^{17}$

Assim, na União Soviética a informação a ser estudada era essencialmente a científica, pois com o crescente aumento da literatura científica produzida era necessário envidar procedimentos de seleção, organização, difusão e acesso à informação científica que foram articulados com o surgimento das novas tecnologias da informação e da comunicação.

Ressalta-se que a ideia propalada pela Informatika soviética foi disseminada pelo mundo e aplicada por diversos estudiosos em vários países, dada a relevância da informação científica, inclusive no Brasil. Entende-se que a Informatika esteve regada a um plano político e corporativo na tentativa de compor uma nova disciplina com uma nomenclatura específica. Todavia, pode-se considerar que a base das atividades desenvolvidas pela Informatika

\footnotetext{
${ }^{17}$ Alexander Ivanovich Mikhailov (1905-1988) foi, por mais de trinta anos (1956-1988), diretor e coordenador do principal orgão de pesquisa em Ciência da Informação na URSS, o Instituto Estatal de Informação Cientifico e Técnica, ou VINITI e por duas vezes vice-diretor da Federação Internacional de Documentação, ou FID (entre 1969-1976 e 1981-1988), onde foi também coordenador de um ramo de pesquisa nessa instituição. Esse autor foi, ainda, dos teóricos que mais contribuíram para a discussão de questões referentes à produção e gestão da informação científica, não só na então União Soviética, mas de parte considerável do extinto bloco socialista. (SANTOS JÚNIOR; PINHEIRO, 2010).
} 
também era desenvolvida na Ciência da Informação em vários locais do mundo aferindo o corporativismo soviético.

Com efeito, é pertinente apresentar que a Ciência da Informação não tem um registro oficial em si, mas é constituída por um conjunto de fatores científicos ou não que levaram ao surgimento da área. Se por um lado, essa quantidade de fatores que originaram a Ciência da Informação dificulta o entendimento sobre o assunto, por outro, mostra que a Ciência da Informação está atrelada a um arcabouço teórico relativamente promissor em termos científicos.

O grande problema reside na fragmentação dos componentes que influenciaram na origem da Ciência da Informação, uma vez que majoritariamente cada fator contribuiu da sua forma para que a Ciência da Informação surgisse, sem uma integração científica mais efetiva. Pode-se identificar que as propostas de Vannevar Bush até a Conferência em 1961/62 nos EUA têm relação direta com os acontecimentos institucionais, técnicos e científicos que marcadamente promoveram a origem e o caminhar da Ciência da Informação (o surgimento ou início de alguma coisa e princípio, começo e ascendência)

Em suma, crê-se que todos os aspectos citados neste capítulo direta ou indiretamente influenciaram na origem da Ciência da Informação de forma mais ou menos intensa, com impactos mais locais ou globais, com perspectivas mais científicas ou profissionais, advindas de uma área tecnológica, cognitiva ou social e humana.

\section{CONSIDERAÇÕES FINAIS}

Conforme disposto no presente artigo, diversos fatores auxiliaram na origem e construção da Ciência da Informação mostrando a sua característica de ciência pós-moderna. Observa-se que não há um contributo principal para o advento da Ciência da Informação, mas um conjunto de ideias, questões e reflexões que foram cruciais para constituir a Ciência da Informação como campo do conhecimento científico.

Percebe-se que a origem da Ciência da Informação ocorre de forma marcante a partir de disciplinas e áreas do conhecimento, como Biblioteconomia e Documentação, assim como a partir de fatores institucionais, como a criação de Associações e a realização de encontros científicos. 
É inegável que os diversos fatores que promoveram a origem da Ciência da Informação, foram cruciais para a caracterização identitária deste campo do conhecimento. É possível observar diversas características identitárias a partir dos elementos que deram vazão a origem da Ciência da Informação, tais como: identidade histórica (relação entre Biblioteconomia e Ciência da Informação); identidade de projeto (a Documentação de Otlet e La Fontaine); identidade partilhada (contribuição dos EUA e do continente europeu para criação da Ciência da Informação) e identidade institucional (criação de associações em Ciência da Informação).

Portanto, observa-se que não há uma identidade da Ciência da Informação específica, mas um conjunto de atributos técnicos, científicos e históricos que compõem marcas identitárias à Ciência da Informação. Verifica-se que a Ciência da Informação é marcada por características identitárias e históricas diversas que variam de acordo com necessidades globais e nacionais.

\section{REFERÊNCIAS}

ANDRADE, Maria Eugênia Albino; OLIVEIRA, Marlene de Oliveira. A Ciência da Informação no Brasil. In: OLIVEIRA, Marlene de. Ciência da Informação e Biblioteconomia: novos conteúdos e espaços de atuação. Belo Horizonte: Editora UFMG, 2005. p. 45-60.

ARAÚJO, Carlos Alberto Ávila. Correntes teóricas da ciência da informação. Ciência da Informação, 2009, vol.38, n.3, pp. 192-204.

AUSTIN, B. Mooer's Law: In and Out of Context. JASIST, Maryland, v 52, n.8, p. 607-609, 2001 .

BARRETO, Aldo Albuquerque. A condição da informação. São Paulo em Perspectiva, São Paulo, v. 16, n. 3, p. 67-74, 2002.

. Uma quase história da ciência da informação. DataGramaZero: Revista de Ciência da Informação, v.9, n.2, abr/08. Disponível em: <http://dgz.org.br/abr08/Art_01.htm>. Acesso em: 16 de janeiro de 2011.

BUCKLAND, Michael. Documentation, Information Science and Library Science in the U.S.A. Information Processing \& Management, v. 32, n. 1, p. 63-76, 1996.

BURKE, Peter. Problemas causados por Gutenberg: a explosão da informação nos primórdios da Europa moderna. Estudos Avançados, v. 16, n. 44, jan./abr., 2002. Disponível em: $<$ http://www.scielo.br/scielo.php?pid=S0103-

40142002000100010\&script=sci_arttext\&tlng=en $>$ Acesso em: 22 jul. 2010. 
BUSH, Vannevar. As we may think. In: Evolution of an information society. London: ASLIB, 1987.

CACALY, Serge (Coord.). Dictionnaire encyclopédique de l'information et de la documentation. Paris: Nathan, 1997. 635 p.

CAPURRO, Rafael. Epistemologia e Ciência da Informação. In: V ENCONTRO NACIONAL DE PESQUISA EM CIÊNCIA DA INFORMAÇÃO, 5., Belo Horizonte, 2003. Anais... Belo Horizonte: Escola de Ciência da Informação da UFMG, 2003.

CASTELLS, Manuel. O poder da identidade. A era da informação: economia, sociedade e cultura. São Paulo: Paz e Terra, v. 2., 2008.

COElHO, Teixeira. Dicionário Crítico de Política Cultural. Cultura e imaginário. 3a edição São Paulo: Iluminuras, 2004.

COUZINET, Viviane; SILVA, Edna Lúcia da; MENEZES, Estera Muszkat. A ciência da informação na França e no Brasil. DataGramaZero, Rio de Janeiro, v. 8, n. 6, 2007. Disponível em: <http://www.dgz.org.br/dez07/Art_03.htm>. Acesso em: 07 fev. 2011.

CRONIN, Blaise. The Sociological Information Science. Journal of Information Science, August, vol. 34, n. 4, p. 465-475, 2008.

DUCHEYNE, Steffen. Paul Otlet's of knowledge and linguistic objectivism. Knowledge Organization, v. 32, n.3, p. 110-116, 2005.

FAYET-SCRIBE, S. Histoire de la documentation en France: culture, science et technologie de l'information, 1895-1937. Paris: CNRS Editions, 2001. (CNRS Histoire).

FERNEDA, Edberto. Recuperação da informação: análise sobre a contribuição da Ciência da computação para a Ciência da Informação. Tese (doutorado em comunicação) - USP. Escola de Comunicação e Artes, São Paulo, 2003.

FIGUEIREDO, Nice. Paul Otlet e o centenário da FID. In: ORGANIZAÇÃ̃o do conhecimento e sistemas de classificação. Brasília: IBICT, 1996.

FREIRE, Gustavo Henrique de Araújo. Ciência da informação: temática, história e fundamentos. Perspectivas em Ciência da Informação, Belo Horizonte, v. 11, n. 1, p. 6-19, jan./abr. 2006.

GÓMEZ, Carlos. Saber y poder político en Gabriel Naudé. Revista de Filosofia, Madrid, v. 5, n. 3, p. 111-132, 2000. Disponível em: $<$ http://revistas.um.es/respublica/article/viewFile/26291/25521>. Acesso em: 12 jan.2011.

HALL, Stuart. A identidade cultural na pós-modernidade. Rio de Janeiro: DP\&A, 1999.

JARDIM, José Maria. FONSECA, M.O. As relações entre a arquivística e a ciência da informação. Cadernos BAD, n. 2, p. 29-45, 1992. 
JOB, Ivone. Estudos cognitivos e a representação do conhecimento na ciência da informação. Revista ACB: Biblioteconomia em Santa Catarina, Florianópolis, v. 13, n. 2, p. 365-378, jul./dez., 2008.

LAHARY, Dominique. Bibliothéconomie. In: CACALY, Serge (Coord.). Dictionnaire encyclopédique de l'information et de la documentation. Paris: Nathan, 1997. 635 p.

LEMOS, Antonio Agenor Briquet de. Bibliotecas. In: CAMPELLO, Bernadete; CALDEIRA, Paulo da Terra. (orgs.). Introdução às fontes de informação. Belo Horizonte: Autêntica Editora, 2005. 184p.

LÓPEZ YEPES, José. La Documentación como disciplina: teoría e historia. 2. ed. Pamplona: Ediciones Universidad de Navarara (EUNSA), 1995.

MATTELART, Armand. História da utopia planetária: da cidade profética à sociedade global. Porto Alegre: Ed. Sulina, 2002.

MORIN, Edgar. Introdução ao pensamento complexo. 2. ed. Lisboa: Instituto Piaget, 1990.

NAUDÉ, Gabriel. Advis pour dresser une bibliothèque. Paris: Klincksieck, 2000.

OTLET, Paul. El tratado de Documentación: el libro sobre El libro: teoria y práctica. Traduzido por Maria Dolores. Ayuso García. Murcia: Universidad de Murcia, 1996. (Tradução de: Traité de documentation: Le livre sur Le livre, théorie et pratiquet. Bruxelles: Mundaneum, 1934).

ORTEGA, Cristina Dotta. Relações históricas entre Biblioteconomia, Documentação e Ciência da Informação. DataGramaZero, v. 5, n. 5, out. 2004.

ORTEGA, Cristina Dotta. Surgimento e consolidação da Documentação: subsídios para compreensão da história da Ciência da Informação no Brasil. Perspectivas em Ciência da Informação, v. 14, número especial, p. 59-79, 2009.

RAYWARD, W. Boyd. The origins of Information Science and the International Institute of Bibliograph/ International Federation for Information and Documentation (FID). Journal of the American Society for Information Science, v. 48, n. 4, p. 289-300, 1997.

ROBREDO, Jaime. Da ciência da informação revisitada aos sistemas humanos de informação. Brasília: Thesaurus, 2003.

SANTOS JÚNIOR, Roberto Lopes dos; PINHEIRO, Lena Vania Ribeiro. A abordagem teórica de A. I. Mikhailov sobre o termo informação científica. Revista Digital de Biblioteconomia e Ciência da Informação, Campinas, v. 7, n. 2, p. 27-45, jan./jun. 2010 . Disponível em: $<$ http://www.sbu.unicamp.br/seer/ojs/viewarticle.php?id=229> Acesso em: 26 jan. 2011.

SARACEVIC, Tefko. Ciência da informação: origem, evolução e relações. Perspectivas em Ciência da Informação, Belo Horizonte, v. 1, n. 1, p. 41-62,jan./jun., 1996. 
SHERA, Jesse. Sociological foundations of librarianship. New York: Asia Publishing House, 1970.

TÁLAMO, Maria de Fátima Gonçalves Moreira; SMIT, Johanna Wilhelmina. Information Science: informational concept and disciplinary integration. BJIS, v.1, n.1, p.30-54, jan./jun. 2007. Available in: <http://www.bjis.unesp.br/>. ISSN: 1981-1640

VANTI, Nadia. Da bibliometria à webometria: uma exploração conceitual dos mecanismos utilizados para medir o registro da informação e a difusão do conhecimento. Ciência da Informação, Brasília, v. 31, n. 2, p. 152-162, maio/ago., 2002.

WERSIG, Gernot. Information science: the study of postmodern knowledge usage.

Information Processing \& Management, v. 29, n. 2, p. 229-239, 1993.

ZINS, Chaim. Redefinindo a Ciência da Informação: da Ciência da Informação para a Ciência do Conhecimento. Informação \& Sociedade: Estudos, João Pessoa, v. 21, n. 3, p. 155-167, set./dez., 2011. 